\title{
The Aetiological Spectrum of Pancytopenia - A Three Year Clinico-Hematological Study.
}

\author{
Authors: Panigrahi $\mathrm{R}^{1}$, Tripathy K $\mathrm{P}^{2}$, Senapati $\mathrm{U}^{3}$. \\ ${ }^{I}$ Dr Ranjita Panigrahi,Associate Professor,Department Of Pathology, Kalinga Institute Of Medical Sciences, \\ Bhubaneswar, Odisha, India. \\ ${ }^{2}$ Dr Krishna Padarabinda Tripathy, AssociateProfessor,Department Of Medicine, Kalinga Institute Of Medical \\ Sciences, Bhubaneswar, Odisha, India. \\ ${ }^{3}$ Dr Urmila Senapati, Professor \&HOD,Department Of Pathology, Kalinga Institute Of Medical \\ Sciences,Bhubaneswar, Odisha, India.
}

\begin{abstract}
Background: Pancytopenia is a common hematological problem in clinical practice. It is not by itself a specific disease but a triad of hematological findings resulting from number of disease processes involving the bone marrow. The severity and the underlying pathology of pancytopenia determines the management and prognosis of the patient. The present study has been undertaken to find out the various causes of pancytopenia by the evaluation of bone marrow findings, so that the data will help the clinicians in the better management of patients.
\end{abstract}

Materials and methods: The study was conducted in the hematology unit of Department of Pathology, KIMS, Bhubaneswar. It was a three year prospective study ( JAN 2013 - DEC 2015) of 92 cases of pancytopenia and included patients of all age groups. Clinical examination, hematological findings, bone marrow aspiration \& biopsy findings were evaluated.

Results: 92 cases of pancytopenia included patients of age ranging from 3 years to $77 y e a r s . T h e r e$ were 48 males \& 44 females with a male to female ratio of $1.1: 1$. Most common cause of pancytopenia was found to be megaloblastic anemia in 45 cases ( 48.9\%) followed by hypoplastic marrow in 14 cases (15.2\%). Among the neoplastic causes of pancytopenia, ALL was the most common (7cases, $7.6 \%$ ).

Conclusion: We conclude that detailed hematological investigations along with bone marrow aspiration and bone marrow biopsy as an adjunct can be very helpful to diagnose and rule out various causes of pancytopenia.

Keywords: Pancytopenia, megaloblastic anemia, bone marrow examination.

\section{Introduction}

Pancytopenia is the simultaneous occurrence of anemia, leucopenia and thrombocytopenia. Therefore it exists when hemoglobin $(\mathrm{Hb})$ is less than $13.5 \mathrm{~g} / \mathrm{dl}$ in males or $11.5 \mathrm{~g} / \mathrm{dl}$ in females; the leucocyte count is less than $4 \times 10^{9} / \mathrm{L}$ and the total platelet count is $<150 \times 10^{9} / \mathrm{L}^{[1]}$. It is not a disease entity but a triad of findings that may result from a number of disease processes - primarily or secondarily involving the bone marrow ${ }^{[2]}$. Varieties of hematopoietic and non hematopoietic conditions manifest with features of pancytopenia. The underlying mechanisms are : decrease in hematopoietic cell production, marrow replacement by abnormal cells, suppression of marrow growth \& differentiation, ineffective hematopoiesis with cell death, defective cell formation which are removed from the circulation, antibody mediated sequestration or destruction of cells and trapping of cells in a hypertrophied and overactive reticuloendothelial system. ${ }^{[2,3]}$ In India , the causes of pancytopenia are not well defined, so the present study is an attempt to evaluate the aetiology of pancytopenia by bone marrow examination.

\section{Materials \& Methods}

The present study was undertaken for a period of 3 years ( January 2013 to December 2015 ) at the hematology unit of the Department of Pathology , KIMS , Bhubaneswar. Patients of both sexes, of all age groups were included in the study.

Inclusion criteria were presence of $\mathrm{Hb}$ less than $13.5 \mathrm{~g} / \mathrm{dl}$ in males and $11.5 \mathrm{~g} / \mathrm{dl}$ in females ; a leucocyte count $<4 \times 10^{9} / \mathrm{L}$ and the platelet count $<150 \times 10^{9} / \mathrm{L}{ }^{[3]}$.Patients receiving myelotoxic chemotherapy were excluded from the study. Relevant clinical history was obtained and physical examination was done. EDTA anticoagulated blood was collected \& processed in Sysmex XS 1000i automated hematology analyser and CBC was obtained. Peripheral smear stained with Leishman stain was studied. Following a written consent, BM aspiration followed by biopsy was carried out under all available aseptic measures under local anaesthesia from the posterior superior iliac crest of patients using Salah and Jamshidi needles respectively. BM aspiration smears were instantly made and touch imprint smears from trephine biopsy material were taken before being sent for 
The Aetiological Spectrum Of Pancytopenia - A Three Year Clinico Hematological Study.

histopathology, preserved in $10 \%$ buffered neutral formalin. Aspiration smears were stained with Leishman stain and special cytochemical stains like PAS and MPO were done where and when required.

\section{Results}

A total number of 235 cases underwent bone marrow examination for various conditions, out of which 92 fulfilled our inclusion criteria and were included in the study.

There were 48 males ( $52.2 \%$ ) and 44 females ( $47.8 \%$ ) with a male to female ratio of 1.1:1. The age of the patients ranged from 3 years to 77 years with an average age of 40 years. Maximum number of cases belonged to the age group of 11 to 20 years ( $42.4 \%$ )

Age \& sex distribution of pancytopenia patients

\begin{tabular}{|l|c|c|c|c|}
\hline Age group( yrs) & Males & $\%$ & Females & $\%$ \\
\hline $1-10$ & 05 & 5.4 & 17 & 18.5 \\
\hline $11-20$ & 23 & 25 & 16 & 17.4 \\
\hline $21-30$ & 01 & 1.1 & 01 & 1.1 \\
\hline $31-40$ & 03 & 3.3 & 04 & 4.3 \\
\hline $41-50$ & 01 & 1.1 & 01 & 1.1 \\
\hline $51-60$ & 09 & 9.8 & 03 & 3.3 \\
\hline $61-70$ & 04 & 4.3 & 02 & 2.1 \\
\hline $71-80$ & 02 & 2.1 & 00 & 0 \\
\hline TOTAL & 48 & 52.2 & 44 & 47.8 \\
\hline
\end{tabular}

The commonest symptom of presentation was weakness and fatigue $(88 \%)$ and the commonest clinical sign was pallor $(100 \%)$ which was seen in all the patients. Other clinical findings were fever, weight loss, bleeding manifestations, dyspnoea, splenomegaly etc. Lymphadenopathy was found in cases of ALL.

Causes Of Pancytopenia Based On Bone Marrow Examination

\begin{tabular}{|l|l|c|c|}
\hline Sl.no & Diagnosis & No.of cases & $\%$ \\
\hline 1 & Megaloblastic anemia & 45 & 48.9 \\
\hline 2 & Hypoplastic/aplastic anemia & 14 & 15.2 \\
\hline 3 & Dual deficiency anemia & 10 & 10.9 \\
\hline 4 & ALL & 07 & 7.6 \\
\hline 5 & AML & 01 & 1.1 \\
\hline 6 & MDS & 01 & 1.1 \\
\hline 7 & NHL & 02 & 2.2 \\
\hline 8 & Erythroid hyperplasia & 04 & 4.3 \\
\hline 9 & Normal marrow & 04 & 4.3 \\
\hline 10 & Hemophagocytosis & 01 & 1.1 \\
\hline 11 & Reactive myeloid hyperplasia & 01 & 1.1 \\
\hline 12 & Multiple myeloma & 01 & 1.1 \\
\hline 13 & Inconclusive & 01 & 1.1 \\
\hline & TOTAL & 92 & 100 \\
\hline
\end{tabular}

The most common cause of pancytopenia was megaloblastic anemia in 45 cases $(48.9 \%)$ followed by hypoplastic / aplastic anemia 14 cases (15.2\%). Dual deficiency anemia was seen in 10 cases (10.9\%). Serum Vit B12 and folic acid levels were available in few cases only. So the exact cause of megaloblastic erythropoiesis with a hypercellular marrow could not be confirmed and it was out of the scope of this study. Eight cases $(8.7 \%)$ of sub leukemic leukemia were diagnosed on bone marrow aspiration which included 7 ALL and 1 AML patient. One case each of multiple myeloma and MDS were seen in our study.

\section{Discussion}

Pancytopenia is a commonly encountered clinico-hematological condition which has multiple causes. Evaluation of the aetiology begins with proper history, physical examination, detailed hematological, biochemical and radiological investigations. Bone marrow aspiration along with biopsy can be used as a safe and easy invasive procedure for investigation of cases of pancytopenia.

Common Causes Of Pancytopenia Compared To Other Studies

\begin{tabular}{|l|l|l|l|l|l|}
\hline Study & Country & Year & $\begin{array}{l}\text { No of } \\
\text { cases }\end{array}$ & $\begin{array}{l}\text { COMMONEST CAUSE } \\
(\%)\end{array}$ & $\begin{array}{l}\text { SECOND MOST COMMON } \\
\text { CAUSE (\%) }\end{array}$ \\
\hline Tilak\&Jain $^{[4]}$ & India & 1999 & 77 & Megaloblastic anemia(68) & Hypoplasticanemia(7.7) \\
\hline Kumar et al $^{[5]}$ & India & 2001 & 166 & Hypoplasticanemia(29.5) & Megaloblastic anemia(22.3) \\
\hline Jha et al $^{[3]}$ & Nepal & 2007 & 148 & Hypoplasticanemia(29.05) & Megaloblastic anemia(23.6) \\
\hline $\begin{array}{l}\text { Khodke K et } \\
\text { al }^{[6]}\end{array}$ & India & 2001 & 50 & Megaloblastic anemia(44) & Hypoplasticanemia(14) \\
\hline
\end{tabular}


The Aetiological Spectrum Of Pancytopenia - A Three Year Clinico Hematological Study.

\begin{tabular}{|l|l|l|l|l|l|}
\hline $\begin{array}{l}\text { Gayathri BN } \\
\text { et al }^{[7]}\end{array}$ & India & 2011 & 104 & Megaloblastic anemia(77) & Hypoplasticanemia(18.26) \\
\hline Present study & India & 2016 & 92 & $\begin{array}{l}\text { Megaloblastic } \\
\text { anemia(48.9) }\end{array}$ & Hypoplasticanemia(15.2) \\
\hline
\end{tabular}

There are varying reports on the underlying cause of pancytopenia from different parts of the world in the literature. Megaloblastic anemia was the most common cause of pancytopenia (48.9\%) in our study which is comparable to other studies. ${ }^{[4,6,7]}$ The high prevalence of nutritional anemia in India has been cited for the increased frequency of megaloblastic anemia.Vitamin B12 deficiency was more common than folate deficiency in our study. Among the nutritional anemias, vitamin B 12 deficiency is more prevalent than folate deficiency as reported by authors in their study from Pakistan. ${ }^{[9]}$ It is a rapidly correctable disorder and should be promptly notified.

In our present study, the peak incidence of megaloblastic anemia was seen in the age group of 21-30 years $(42.4 \%)$ which was similar to that reported by Khanduri et al $(48 \%) .{ }^{[8]}$

Incidence of hypoplastic anemia/ aplastic anemia varies from $7 \%$ to $30 \%$ among pancytopenia patients ${ }^{[3,4,5,6,7]}$. In our study it was $15.2 \%$ which was comparable to Khodke $\mathrm{K}$ et al ${ }^{[6]}$ and Khunger JM et al ${ }^{[1]}$. Both observed an incidence of $14 \%$.

The incidence subleukemic leukemia in our study was $8.7 \%$ as compared to $5 \%$ reported by Khunger JM et al. ${ }^{[1]}$

\section{Conclusion}

We conclude that the most common cause of pancytopenia is megaloblastic anemia. Dual deficiency anemia and hypoplasticanemia are other important causes. This seems to reflect the higher prevalence of nutritional anemia in our subpopulation. Bone marrow examination is a useful investigation which easily reveals the underlying cause in most of the cases.

\section{References}

[1]. Khunger JM, Arculselvi S, Sharma U, Ranga S, Talib VH. Pancytopenia-A Clinico-hematological study of 200 cases. Indian J PatholMicrobiol. 2002;45:375-9. [PubMed]

[2]. Guinan EC, Shimamura A. Wintrobe's Clinical Hematology. In: Greer JP, Foerster J, Lukens JN, Rodgers GM, Paraskevas F, Glader B, editors. Acquired and inherited aplastic anemia syndromes. 11th ed. Philadelphia: Lippincott Williams and Wilkins; 2004. pp. 1397-419.

[3]. Jha A, Sayami G, Adhikari RC, Panta AD, Jha R. Bone MarrowExaminations in cases of Pancytopenia. J Nepal Med Assoc2008; 47:12-7.

[4]. Tilak V, Jain R. Pancytopenia-A Clinco-hematologic analysis of 77 cases. Indian J PatholMicrobiol. 1992;42:399-404. [PubMed]

[5]. Kumar R, Kalra SP, Kumar H, Anand AC, Madan M. Pancytopenia-A six year study. J Assoc Physicians India. 2001;49:107981. [PubMed]

[6]. Khodke K, Marwah S, Buxi G, Vadav RB, Chaturvedi NK. Bone marrow examination in cases of pancytopenia. J Academy Clin Med. 2001;2:55-9.

[7]. B N Gayathri and Kadam Satyanarayan Rao. Pancytopenia: a clinico hematological study. J Lab Physicians. 2011; volume 3: issue no.1, p15-20.

[8]. Khanduri U, Sharma A. Megaloblastic anaemia: prevalence and causative factors. Natl Med J India. 2007 ;20:172-5.

[9]. Modood-ul-Mannan, Anwar M, Saleem M, Wiqar A, Ahmad M. A Study of serum vitamin B12 and folate levels in patients of megaloblastic anemia in northern Pakistan. J Pak Med Assoc. 1995 ; 45: 187-88. 